\title{
Long aftershock sequences in North China and Central US: implications for hazard assessment in mid-continents
}

\author{
Mian Liu · Gang Luo $\cdot$ Hui Wang • \\ Seth Stein
}

Received: 17 September 2013/Accepted: 8 January 2014/Published online: 2 February 2014

(c) The Seismological Society of China, Institute of Geophysics, China Earthquake Administration and Springer-Verlag Berlin Heidelberg 2014

\begin{abstract}
Because seismic activity within mid-continents is usually much lower than that along plate boundary zones, even small earthquakes can cause widespread concerns, especially when these events occur in the source regions of previous large earthquakes. However, these small earthquakes may be just aftershocks that continue for decades or even longer. The recent seismicity in the Tangshan region in North China is likely aftershocks of the 1976 Great Tangshan earthquake. The current earthquake sequence in the New Madrid seismic zone in central United States, which includes a cluster of $M \sim 7.0$ events in 1811-1812 and a number of similar events in the past millennium, is believed to result from recent fault reactivation that releases pre-stored strain energy in the crust. If so, this earthquake sequence is similar to aftershocks in that the rates of energy release should decay with time and
\end{abstract}

\section{Liu}

Department of Geological Sciences, University of Missouri, Columbia, MO 65211, USA

M. Liu ( $\square)$

The Key Laboratory of Computational Geodynamics, Chinese Academy of Sciences, Beijing 100049, China

e-mail: lium@missouri.edu

G. Luo

Bureau of Economic Geology, Jackson School of Geosciences, University of Texas at Austin, Austin, TX 78713, USA

\section{H. Wang}

Institute of Earthquake Science, China Earthquake

Administration, Beijing 100036, China

S. Stein

Department of Earth and Planetary Sciences, Northwestern University, Evanston, IL 60208, USA the sequence of earthquakes will eventually end. We use simple physical analysis and numerical simulations to show that the current sequence of large earthquakes in the New Madrid fault zone is likely ending or has ended. Recognizing that mid-continental earthquakes have long aftershock sequences and complex spatiotemporal occurrences are critical to improve hazard assessments.

Keywords Aftershock - Earthquake - Intraplate seismicity $\cdot$ Earthquake hazard

\section{Introduction}

On May 2012, an $M 4.8$ earthquake occurred near Tangshan, an industrial city about $150 \mathrm{~km}$ east of Beijing (Fig. 1). This moderate earthquake caused widespread concerns that were intensified by a subsequent sequence of smaller earthquakes, including an $M 4.0$ event on June 18, 2012. There were good reasons for concern-the great Tangshan earthquake ( $M$ 7.8) in 1976 destroyed this heavily populated city and killed more than 242,000 people (Chen et al. 1988). Although more than 30 years has passed and a new Tangshan city has been built upon the ruins, the memory of devastation is still fresh. Are these recent Tangshan earthquakes precursors of a new period of active seismicity in Tangshan and the rest of North China? Or are they the aftershocks of the great Tangshan earthquake?

Answers to these questions have different implications for earthquake hazard assessment in this region, the socalled "Capital Circle" in China that includes Beijing and a number of other megacities and is the heart of Chinese politics and economy. Those who rejected the notion of the recent Tangshan seismicity as aftershocks pointed to the 

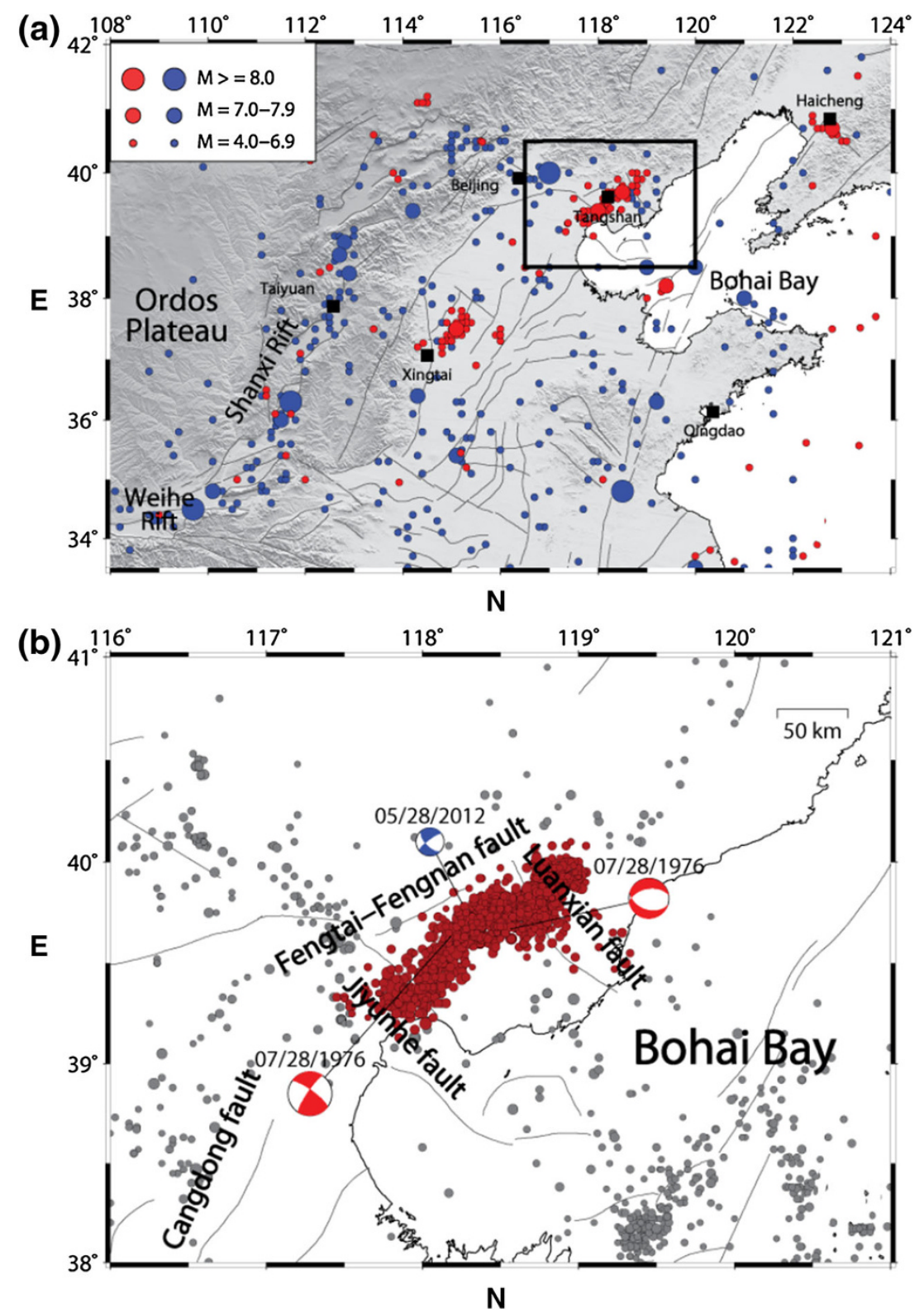

Fig. 1 a Relief map, faults (lines), and seismicity (dots, $M \geq 3.0,1970-2011)$ in North China and surrounding regions. Box shows the Tangshan region in (b). b Seismicity in the source region of the 1976 Tangshan earthquake. Red dots are epicenters of aftershocks; gray dots are background seismicity $(M \geq 3.0,1970-2011)$. The focal mechanism solutions are for the two mainshocks of 1976 (red beach balls) and the May 5, 2012 event (blue beach ball)

fact that more than 30 years has passed, since the great Tangshan earthquake. Indeed most aftershock sequences are short, lasting for a few months to a few years after the mainshocks (Parsons 2002). However, Stein and Liu (2009) have suggested that aftershock sequences may last much longer in mid-continents where tectonic loading is slow, such as in North China.

In mid-continents where large earthquakes are rare and infrequent, it is challenging to forecast where future earthquakes will likely occur. Moreover, because of the low overall seismicity, aftershocks may be misinterpreted as precursors. In this study, we compare seismic history and hazard maps in North China and central US to highlight the challenge we face and suggest ways to improve.

\section{North China}

The North China craton (or block) is exceptional-it was thermally rejuvenated since the Mesozoic (Zhu et al. 2012), and has been seismically active (Liu and Yang 2005). More than 100 large $(M>6)$ earthquakes occurred here, since 23 


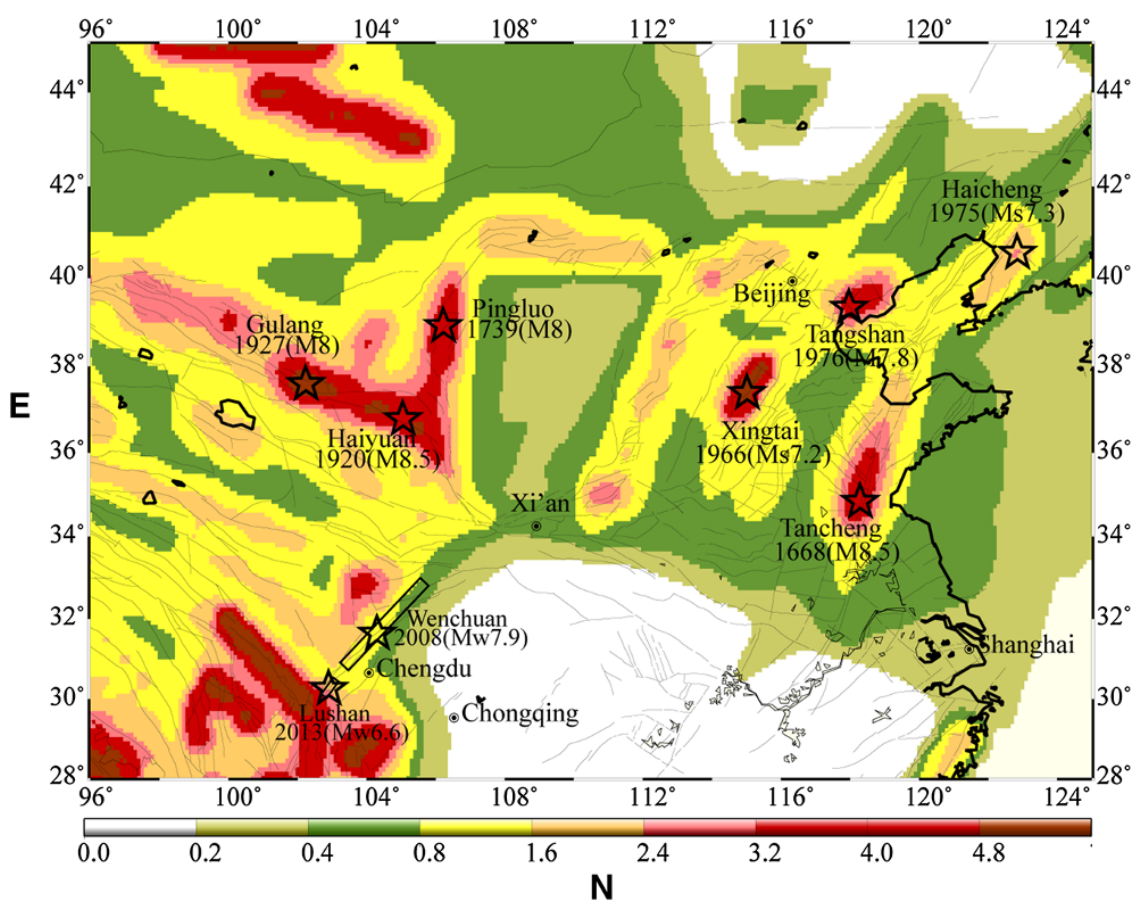

Fig. 2 Seismic hazard map for North China and surrounding regions (GSHAP 1999). The hazard is expressed as the peak ground acceleration (PGA) on firm rocks, in $\mathrm{m} / \mathrm{s}^{2}$, expected to be exceeded in the next 50 years with a probability of $10 \%$. The rupture zones of the 2008 Wenchuan earthquake $\left(M_{N} 7.9\right)$ and 2013 Lushan earthquakes $\left(M_{N} 6.6\right)$ are indicated by boxes

BC, including the 1556 Huaxian earthquake $(M 8.3)$ that reportedly killed 830,000 people.

\subsection{Seismicity and hazard assessment}

Earthquake records in North China extend back nearly 3,000 years, showing at least thirteen great $(M \geq 8)$ events (Gu et al. 1983). Liu et al. (2011) examined the spatiotemporal pattern of large earthquakes in North China and found that these earthquakes seem to have roamed between distant fault systems, some of which were recognized only after the large earthquakes occurred. This is the case for the 1976 Tangshan earthquake and the two other devastating earthquakes in the past century: the $M 7.2$ Xingtai earthquake in 1966 and the $M 7.5$ Haicheng earthquake in 1975 (Fig. 1). Furthermore, Liu et al. (2011) noted that no large $(M \geq 7.0)$ events ruptured the same fault segment twice or more during the past 2000 years.

Such complex spatiotemporal patterns of earthquakes pose a serious challenge to the assessment of earthquake hazards. Figure 2 is the hazard map for North China and surrounding regions, made by the Global Seismic Hazard Assessment Program (GSHAP). Comparing it with Fig. 1a, one can see that the hazard assessment was heavily influenced by the occurrence of previous large earthquakes. The Tangshan, Xingtai, and Haicheng areas are assigned a high risk because of the recent large earthquakes there. The southern segment of the Tanlu fault, whose rupture in 1668 produced the $M 8.5$ Tancheng earthquake, is also assigned high risk. All other regions shown as high risk are where large earthquakes occurred previously.

Given the complex spatiotemporal history of large earthquakes in North China (Liu et al., 2011), the current practice of hazard assessment, which relies heavily on the record of previous earthquakes, is questionable (Stein et al., 2012). Since the publication of this hazard map in 1999, a number of large earthquakes occurred in this region, all of which were missed by the hazard map. The 2008 Wenchuan earthquake $\left(M_{N} 7.9\right)$, which killed $\sim 90,000$ people, was unexpected by the map (Fig. 2), presumably because of the low fault slip rates $(<3 \mathrm{~mm} / \mathrm{a})$ on the hosting Longmenshan fault, and the lack of large earthquakes there in the past centuries. The 2013 Lushan earthquake $\left(M_{N}\right.$ 6.6), which ruptured the southern segment of the Longmenshan fault, was also missed by the hazard map (Fig. 2).

Stein et al. (2012) discussed major factors that can cause the hazard maps to fail. Some are due to the limitations of available data - earthquake catalogs in most regions are too short to provide a complete picture of earthquake recurrences. This is true even for North China, where the earthquake record is among the longest in the world. More important factors, however, have to do with the defects in our fundamental models of earthquakes. The underlying assumptions that go into current hazard assessment are that large earthquakes will repeat in the same places, and small earthquakes are indicators of stress buildup toward the next large earthquake. These assumptions have their root in the 
elastic rebound model, first proposed by Reid (1910) in the aftermath of the 1906 San Francisco earthquake. The elastic rebound model of cyclic stress buildup and release on a fault segment works nicely for earthquakes in plate boundary zones, where the steady relative plate motion loads faults at constant rates, causing repeated ruptures. However, in midcontinents like North China, the faults are not loaded directly by steady plate motion. Instead, each fault is part of a complex dynamic system of widespread faults that interact with each other and collectively accommodate the tectonic loading at far-field plate boundaries. Because of the slow far-field loading, local stress perturbations, either due to ruptures of distant faults or surface loading by erosion and sedimentation, could become important (Liu et al. 2011). Consequently, on timescales of hundreds to thousands of years, large earthquakes tend to roam between widely distributed faults, as in North China (Fig. 1).

\subsection{Long sequence of aftershocks in Tangshan}

The spatial roaming of large earthquakes between widespread faults makes hazard assessment difficult. Further challenges arise if the small earthquakes we see today are aftershocks of large earthquakes that occurred a long time ago. Distinguishing long sequences of aftershocks from precursors of future large earthquakes or background seismicity may not be easy because of the short instrumental records. We now go back to the question raised at the beginning of this paper: Are the recent Tangshan earthquakes aftershocks?

By definition (Liu and Stein 2011), aftershocks are earthquakes that follow the mainshock in its source region. Their magnitudes are usually smaller than that of the mainshock (Båth's law), and their numbers decay exponentially with time (Omori's law). Seismicity in the source region of the 1976 Tangshan earthquake is shown in Fig. 1b. Local seismic networks in Tangshan and the rest of China were established in 1970, recording background seismicity before the 1976 earthquake. Figure 3 shows that both the seismicity and seismicity rates have been decaying, as expected from Omori's law of aftershocks, and the level of seismicity is still clearly higher than the background, indicating that aftershocks of the 1976 earthquake continue today.

Additional evidence for continuing aftershock sequences in the Tangshan, Xingtai, and Haicheng regions has been found from analyzing the seismicity rates and the strain rates (Liu and Wang 2012). These data show that aftershock sequences in North China can last for at least a few decades, much longer than typical for plate boundary zone earthquakes.

\section{Central US}

A different example of long aftershock sequences in midcontinent may be found in the central United States' New

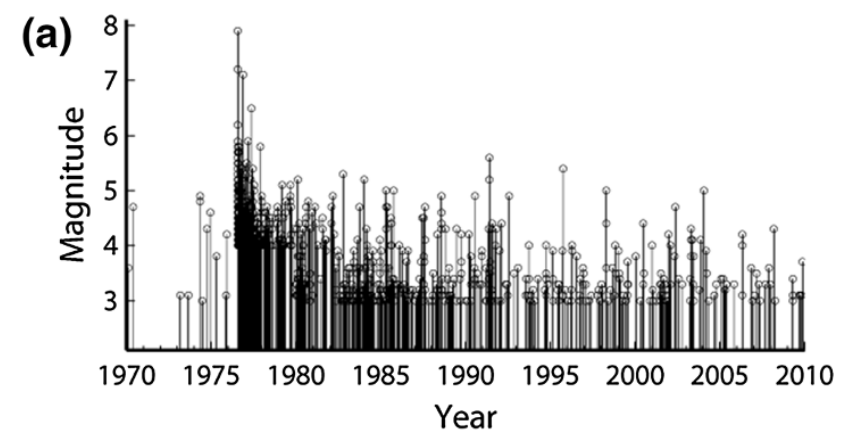

(b)

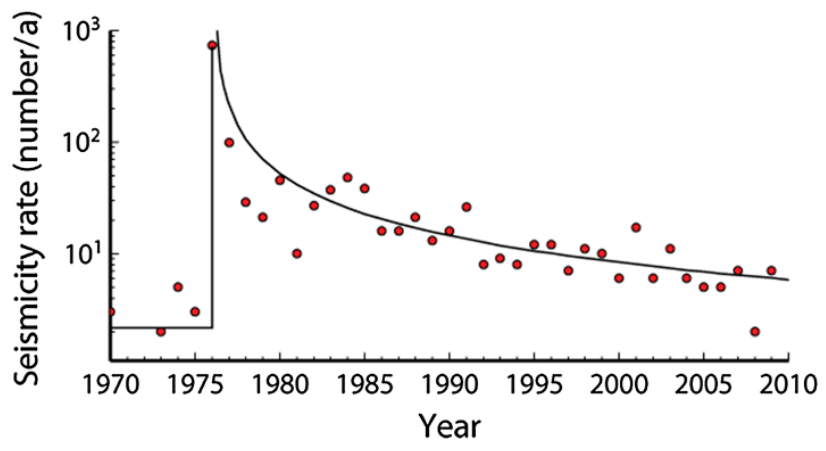

Fig. 3 a Earthquake sequence in the source region of the 1976 Tangshan earthquake. b Seismicity rates (number of events per year) of the Tangshan earthquake sequence. Solid lines are least square fitting (Liu and Wang 2012)

Madrid seismic zone (NMSZ) (Fig. 4a), where at least three large earthquakes occurred between 1811 and 1812. Early studies put the magnitudes of these events to $M \geq 8.0$ (Johnston 1996); recent estimates of their magnitudes are around 7.0 (Hough and Page 2011). In contrast to the spatially roaming large earthquakes in North China, paleoseismic evidence indicates that similar events occurred in the NMSZ around 1450 and $900 \mathrm{AD}$, in addition to some earlier but less well-constrained events (Tuttle et al. 2002). Because these data seem to suggest that large earthquakes in the NMSZ recur $\sim 500$ years apart, a high level of hazard is assigned to this region (Fig. 4a).

The paleoseismic evidence for repeated large earthquakes in the NMSZ, however, is inconsistent with the observed surface strain rates. Earthquakes occur by releasing accumulated strain energy on faults. Because a magnitude 7 earthquake would cause 1-2 m fault slip, producing one every 500 years requires a $2-4 \mathrm{~mm} /$ year slip rate across the fault zone. This rate of motion across the NMSZ cannot result from steady tectonic loading-the NMSZ is in the middle of the nearly rigid central and eastern United States (Dixon et al. 1996), and the overall relative motion across the NMSZ is less than $0.2-0.4 \mathrm{~mm} /$ year (Calais and Stein 2009; Frankel et al. 2012). 
(a)

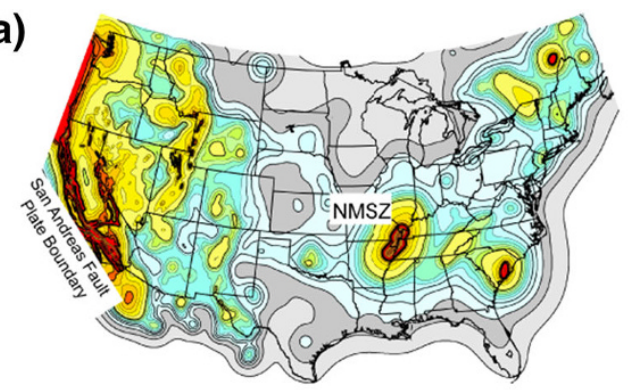

(c)

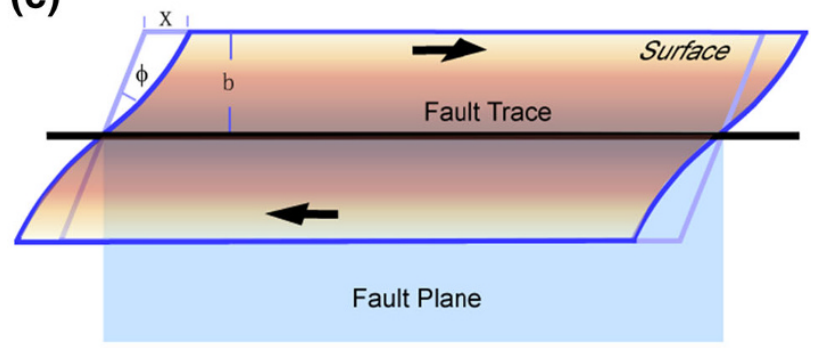

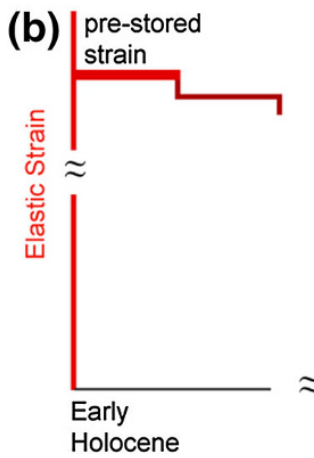
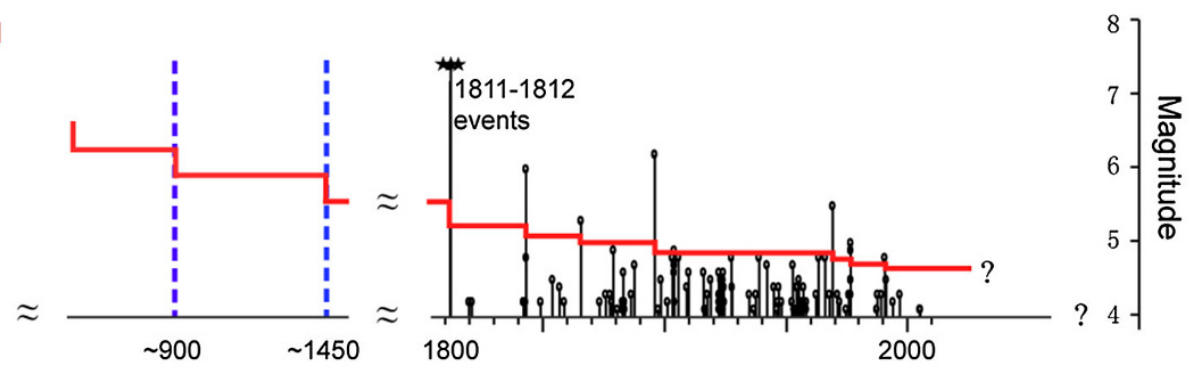

Fig. 4 a US Geological Survey earthquake hazard map showing the New Madrid seismic zone (NMSZ) with hazard comparable to California's, based on assumption that large earthquakes continue in the NMSZ. b Conceptual model of a decaying NMSZ earthquake sequence, showing large earthquakes during 1811-1812 and similar events around 900 and 1450 AD, and smaller events, since 1812. c Simple model for strain accumulation on a strike-slip fault

One explanation for this discrepancy is that the NMSZ earthquakes result from recent fault reactivation (Schweig and Ellis 1994), releasing elastic strain energy previously stored in the crust. Such recent reactivation is consistent with the lack of significant topography or deformation of young strata in the area (Schweig and Ellis 1994) and an increase in slip rate during the Holocene $(\sim 10,000$ years ago) (Van Arsdale 2000). Proposed triggers for this reactivation include stress perturbation due to erosional-depositional processes (Calais et al. 2010), or glacial isostatic adjustment (Grollimund and Zoback 2001) coupled with recent local weakening of the crust (Kenner and Segall 2000; McKenna et al. 2007).

If the current NMSZ seismicity mainly releases pre-stored strain energy in the crust, it is analogous to an aftershock sequence in that the rate of energy release would decay with time. Thus, in contrast to the repeated earthquakes at plate boundaries, this sequence of earthquakes will eventually end (Fig. 4b). The lack of present-day surface stain accumulation may indicate that this sequence of earthquakes has ended or is ending (Stein 2010). Whether this is true has important implication for hazard assessment. Here we estimate how long this sequence of large earthquakes could last using simple physical analysis and numerical modeling.

\subsection{A simple analysis of releasing pre-stored energy}

If the energy source powering the recent NMSZ earthquakes is primarily pre-stored strain energy in the crust, the amount of pre-stored strain energy limits how long the earthquake sequence can last. Some estimates may be derived from a simple model of a strike-slip fault on which strain energy accumulates due to relative motion across the fault when it stays locked (Fig. 4c.). The elastic strain $(\varepsilon)$ is measured by the angle $\phi$ between a line initially perpendicular to the fault trace and its current location due to shearing: $\varepsilon=\tan \phi=x / b$, where $b$ is the half width of the fault zone and $x$ is the displacement in far field, which is a measure of the cumulative fault slip needed to completely release the elastic strain. The total strain that can be stored is limited by the yielding shear stress on the fault: $\tau_{\max }=G \varepsilon=G x / b$, where $G$ is the shear modulus.

The values of $b$ and $G$ are relatively well constrained (Hough and Page 2011). The value of $\tau_{\max }$ should be higher than the stress drops during large earthquakes, typically a few MPa, because it is the yielding shear stress on the fault prior to its reactivation. Taking $\tau_{\max }=20 \mathrm{MPa}$, the value of the maximum tectonic shear stress in unfaulted crust in many places (McGarr and Gay 1978), and hence likely an upper limit, $b=50 \mathrm{~km}$, and $G=30 \mathrm{GPa}$, yields $x=33 \mathrm{~m}$. This is the total slip on the fault needed to completely release the stored strain. For a sequence of earthquakes 500 years apart with $2 \mathrm{~m}$ of seismic slip each, the stored strain can produce 17 events and the sequence would last 8,000 years. A similar sequence of larger events with greater slip would end sooner. Furthermore, the release of pre-stored strain is unlikely to be steady. Instead, 


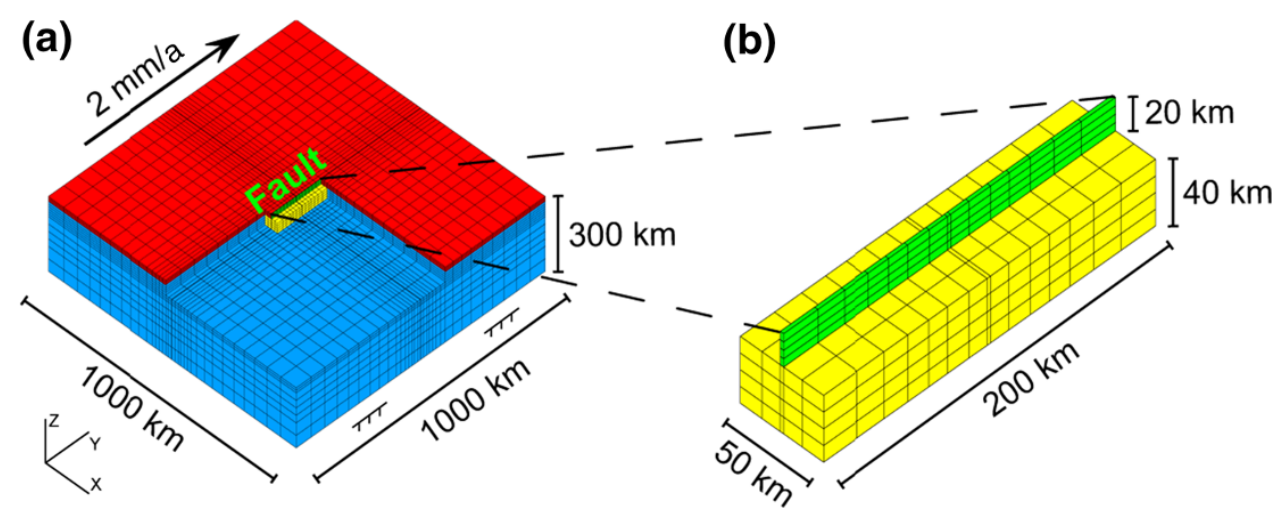

Fig. 5 a Finite element model of an intraplate strike-slip fault. b Enlargement of the fault zone (green), which is simulated by a 2-km thick elastoplastic fault plane on top of relatively weak zone (yellow) of the lower crust and upper mantle

it should follow a decay pattern like Omori's law for aftershocks, with more energy released during early stages. If so, the sequence should be shorter than these estimates.

The total dip-slip offset on the Reelfoot fault, the central segment of the NMSZ, is about $70 \mathrm{~m}$ (Schweig and Ellis 1994; Van Arsdale and TenBrink 2000). If all this offset are due to release of pre-stored strain, our estimate of the initial strain accumulation is off by a factor of 2 , and the large NMSZ earthquakes would have already continued for more than 16,000 years at the estimated pace. Hence even assuming the previously accumulated strain is higher than our estimate and the earthquake sequence started later, say 10,000 years ago, the sequence should be close to ending or have ended.

\subsection{A numerical model of energy transfer}

In this simple analysis, the sequence of large earthquakes continues until the pre-stored strain has been released. Continued tectonic loading would prolong this sequence. However, GPS data (Calais et al. 2006; Frankel et al. 2012) and evidence for recent reactivation of the NMSZ faults (Schweig and Ellis 1994) indicate at most very slow tectonic loading across the entire seismic zone. Additional complication may arise from viscous relaxation in the lower crust and upper mantle, which could transfer some stress released during fault rupture back to the upper crust and produces repeated earthquakes (Kenner and Segall 2000). This cycling of stress may prolong the release of the pre-stored energy, but it does not add new strain energy to the system.

We used a finite element model to explore how stress cycling associated with viscous relaxation may prolong the earthquake sequence (Fig. 5). The model setting is similar to that of Kenner and Segall (2000). The model domain is a $1,000 \times 1,000 \mathrm{~km}$ area extending to $300-\mathrm{km}$ depth, with a $20-\mathrm{km}$ thick elastic upper crust on top of a viscoelastic lower crust and upper mantle. The fault is a 200-km long and $2-\mathrm{km}$ wide elastoplastic vertical zone cutting across the seismogenic upper crust. Below the fault zone is a $50-\mathrm{km}$ wide and 40-km thick weak zone, embedded in the relatively stronger surrounding lower crust and upper mantle. Young's modulus is $8.75 \times 10^{10} \mathrm{~Pa}$ and Poisson's ratio is 0.25 for the whole model domain. A range of viscosity values for the weak zone and the surrounding ductile lower lithosphere were tested.

The model domain was first loaded by imposing a $2 \mathrm{~mm} /$ year right-lateral velocity on the left side; motion on the right side is fixed in the $x$ and $y$ directions. The front and back sides are fixed in the $x$ direction and free in the $y$ and $z$ directions. The surface is free; the bottom is fixed vertically but free to move horizontally. The model domain was loaded until the shear stress in the seismogenic crust reached a certain value (34 $\mathrm{MPa}$ in most cases), at which point the imposed loading stopped, and the resulting stress state of the model crust was used as the initial condition for the recent activation of the NMSZ. We then explored how viscous relaxation produces repeated earthquakes and what controls the duration of the earthquake sequence.

Earthquakes are simulated by strain softening of the elastoplastic fault elements, whose plastic yield strength is initially specified by an internal friction angle of $5^{\circ}$ and a cohesion of $30 \mathrm{MPa}$ (Luo and Liu 2010). The first event is simulated by a sudden drop of the cohesion of all fault elements to $20 \mathrm{MPa}$. This produces $\sim 8 \mathrm{~m}$ average slip on the entire fault plane, which is equivalent to an $M w \sim 8$ earthquake. This event causes coseismic loading of the surrounding crust and the underlying ductile lower lithosphere. Viscous relaxation in the lower lithosphere then shifts some of the stress back to the seismogenic upper crust, causing failure of some or all of the fault elements. The cycling of stress between the fault plane and the ductile lower lithosphere continues until the perturbing stress becomes too low to cause further failures (Fig. 6). 
(a) no dissipation

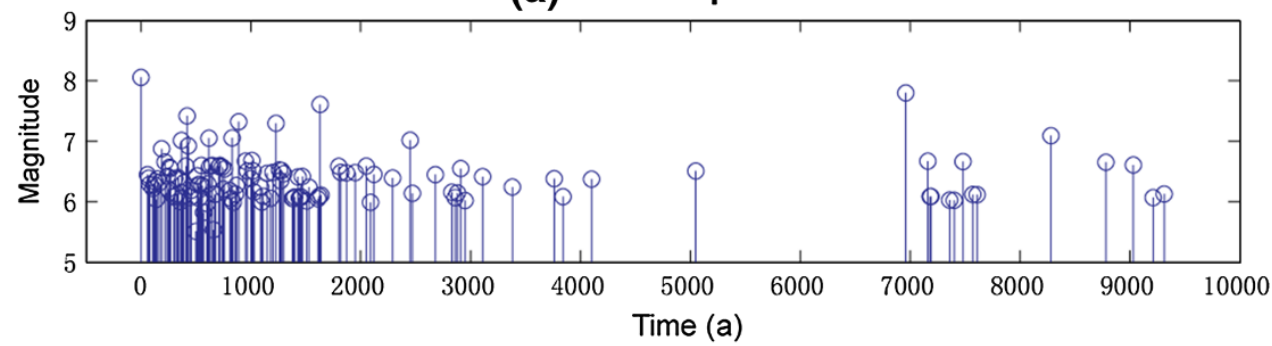

(b) $50 \%$ dissipation

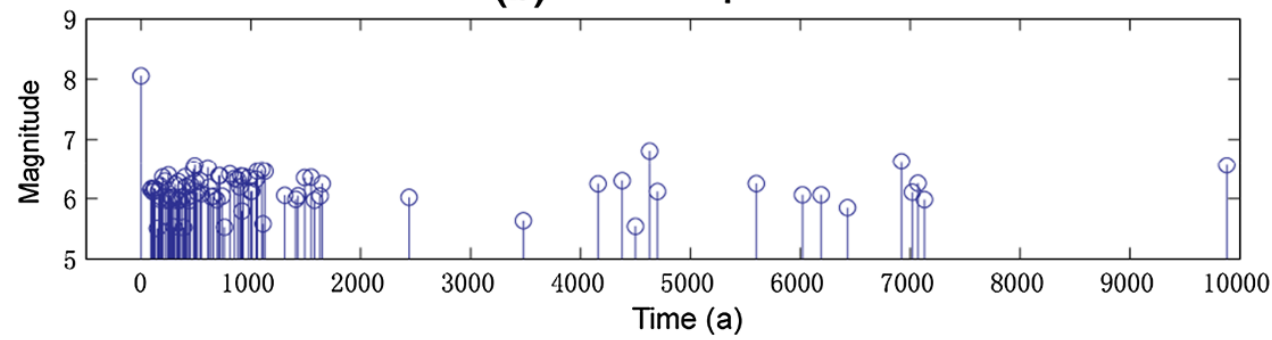

(c) $95 \%$ dissipation

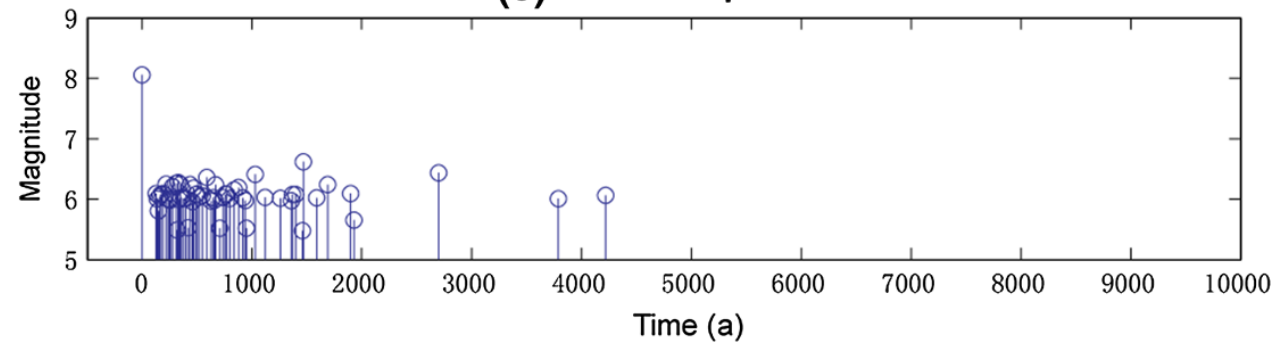

Fig. 6 Simulated earthquake sequences with stress cycling due to viscous relaxation in the ductile lower lithosphere. a Pure visco-elastic process, with no energy dissipation during each rupture. b During each rupture, $50 \%$ of the strain energy released is dissipated in non-elastic processes, so coseismic loading of the ductile lower lithosphere and stress recycled back to the upper crust by viscous relaxation is half those for the pure viscoelastic case. c As in (b) with $95 \%$ of strain energy dissipation in each rupture

The resulting earthquake sequence includes repeated large earthquakes with decreasing frequency, and the sequence lasts for about 10,000 years (Fig. 6a). However, in this case, as in the model of Kenner and Segall (2000), the stress cycling is assumed to be purely viscoelastic, so strain energy released by rupturing is entirely propagated down into the ductile lower lithosphere (and the surrounding crust) and later recycled back to the upper crust by viscous relaxation. This is certainly not realistic; during earthquakes, a large portion of strain energy is dissipated in heat and other non-elastic processes, although the energy partition between seismic and aseismic processes is uncertain (Kanamori 1978; Lockner and Okubo 1983), and only a fraction of the strain energy in the upper crust will be eventually used for earthquakes (Ward 1998).

If we assume that during each rupture, $50 \%$ of strain energy is dissipated by heat and other non-elastic processes, the resulting earthquake sequence will have smaller and fewer earthquakes than that in Fig. 6a and effectively ends after $\sim 7,000$ years (Fig. 6b). If most of the strain energy is dissipated during ruptures, a more likely scenario (Kanamori 1978), the resulting earthquake sequence will end much sooner (Fig. 6c).

The duration and characteristics of the stress decay process depend also on the rheological structure of the model. In general, the lower the viscosity of the ductile lower lithosphere, the faster the viscous relaxation, and thus the shorter duration of the earthquake sequence. Assuming the total duration of the sequence to be less than 10,000 years, Kenner and Segall (2000) estimated the viscosity of the lower crust to be $10^{21}-10^{22} \mathrm{~Pa}$ s. For the results in Fig. 6, we assumed a weak zone $\left(1 \times 10^{20} \mathrm{~Pa} \mathrm{~s}\right)$ imbedded in a ductile lower lithosphere $\left(2 \times 10^{21} \mathrm{~Pa} \mathrm{~s}\right)$. We also explored other rheological structures, including a weak zone extending deeper under the NMSZ (Zhang et al. 2009a, b). Although the results would vary with rheological values and structures, the general pattern remains the same. The key factor controlling the sequence duration is the fraction of strain energy dissipation during ruptures-the more dissipation, the shorter the sequence. 


\section{Discussion and conclusions}

The long aftershock sequences in North China and central US show fundamental differences between earthquakes in mid-continents and at plate boundaries. The major cause for this difference is the loading conditions (Liu et al. 2011). The slow tectonic loading within continents cause long aftershock sequences (Stein and Liu 2009), as predicted by the rate and state frictional law (Dieterich 1994). In contrast, plate boundary faults are loaded more rapidly by steady relative plate motion. Consequently, earthquakes concentrate along the plate boundary faults, and quasiperiodic occurrences may be expected. As long as the relative plate motion continues, so will the earthquake sequences. The situation is quite different in mid-continents, where slow tectonic loading is shared by a complex system of interacting faults spread over a large region. Each fault is not loaded by steady relative motion between crustal blocks on either side, and its loading rate may be affected by a large earthquake on other faults ( $\mathrm{Li}$ et al. 2009). Consequently, individual faults may remain dormant for a long time and then become active for a short period, leading to episodic and spatially migrating earthquakes.

Such complex spatiotemporal patterns of large earthquakes are observed in other mid-continents, including Australia and northwestern Europe (Camelbeeck et al. 2007; Clark and McCue 2003). Although the repeated large earthquakes in the New Madrid seismic zone during the past millennium may seem to be an exception to this complex pattern of mid-continental earthquakes, they nonetheless differ fundamentally from earthquakes at plate boundary zones because they cannot result from steady tectonic loading. Whether they release pre-stored strain energy on reactivated faults or have other causes, the transient loading causes a transient earthquake sequence. Using both a simple physics model and a viscoelastic numerical model indicate, we have shown that the current sequence of New Madrid earthquakes is likely ending or has ended. Such results are consistent with geodetic observations that show less than $0.2-0.4 \mathrm{~mm} /$ year relative motion across the NMSZ fault zone (Calais et al. 2010; Frankel et al. 2012). Although the recent seismicity in central US is dominated by the NMSZ earthquakes, paleoseimic evidence indicates large Quaternary earthquakes in other parts of the Mississippi Embayment and beyond (Cox et al. 2000; Tuttle et al. 2006). The Meers fault in Oklahoma, for example, had a large earthquake some 12,000 years ago but is quiet today. Hence, large earthquakes have roamed between widespread faults in central US, similar to earthquakes in North China.

Both the long aftershock sequences of mid-continental earthquakes and their complex spatiotemporal occurrences make hazard assessment, a challenging task even at plate boundaries, even more difficult. Although aftershocks can still be damaging and need to be included in hazard assessment, they are poor predictors of future large earthquakes. Moreover, because large earthquakes tend to migrate between distant faults, large earthquakes in midcontinents often not repeat on the same fault segment within hundreds to thousands of years. To improve assessments of earthquake hazard, we need to go beyond the current models that treat individual faults or fault segments as isolated systems and focus on cyclic stress buildup and release on these faults. Instead, we have to treat the widespread faults within continents as complex systems and try to understand how the faults interact with each other (Li et al. 2009; Stein et al. 2009). Earthquake records need to be combined with paleoseismic studies to develop a longer earthquake history, and high precision GPS measurements need to go beyond the sites of recent large earthquakes. All these require time and effort, but realizing the problems of current practice, as we have shown in this study, is the necessary first step toward a better assessment of earthquake hazards.

Acknowledgments Liu's work in North China is supported by NSF-PIRE Grant OISE-0730154 and the University of Chinese Academy of Science. Wang's work is supported by the International Science and Technology Cooperation Program of China grant (2010DFB20190) and the National Natural Science Foundation of China (Grants Nos. 41104058 and 41104057). Gang Luo acknowledges support from the Opening Fund of State Key Laboratory of Geohazard Prevention and Geoenvironment Protection (Chengdu University of Technology) (SKLGP2012K030).

\section{References}

Calais E, Stein S (2009) Time-variable deformation in the New Madrid Seismic Zone. Science 323(5920):1442

Calais E, Han JY, DeMets C, Nocquet JM (2006) Deformation of the North American plate interior from a decade of continuous GPS measurements. J Geophys Res B 111:6

Calais E, Freed AM, Van Arsdale R, Stein S (2010) Triggering of New Madrid seismicity by late-Pleistocene erosion. Nature 466(7306):608-611

Camelbeeck T, Vanneste K, Alexandre P, Verbeeck K, Petermans T, Rosset P, Everaerts M, Warnant R, Van Camp M (2007) In: Stein S, Mazzotti S (eds) Relevance of active faulting and seismicity studies to assess long term earthquake activity in Northwest Europe, vol 425. Geological Society of America, Kansas, pp 193-224

Chen Y, Tsoi KL, Chen FB, Gao ZH, Zou QJ, Chen ZL (1988) The great Tangshan earthquake of 1976: an anatomy of disaster. Pergamon Press, Oxford, p 153

Clark D, McCue K (2003) Australian paleoseismology: towards a better basis for seismic hazard estimation. Ann Geophys 46(5):1087-1106

Cox RT, Van Arsdale RB, Harris JB, Forman SL, Beard W, Galluzzi J (2000) Quaternary faulting in the southern Mississippi embayment and implications for tectonics and seismicity in an intraplate setting. Geol Soc Am Bull 112(11):1724-1735 
Dieterich J (1994) A constitutive law for rate of earthquake production and its application to earthquake clustering. J Geophys Res 99(B2):2601-2618

Dixon TH, Mao A, Stein S (1996) How rigid is the stable interior of the North American plate? Geophys Res Lett 23:3035-3038

Frankel A, Smalley R, Paul J (2012) Significant motions between GPS sites in the New Madrid region: implications for seismic hazard. Bull Seismol Soc Am 102(2):479-489

Grollimund B, Zoback MD (2001) Did deglaciation trigger intraplate seismicity in the New Madrid seismic zone? Geology (Boulder) 29(2): $175-178$

GSHAP (Global Seismic Hazard Assessment Program) (1999) Global Seismic Hazard Map. http://www.seismo.ethz.ch/static/GSHAP/

Gu GX, Lin TH, Shi ZL, Li Q (1983) Earthquake catalog of China: 1831 B.C. -1969 A.D. Science Press, Beijing (in Chinese)

Hough S, Page M (2011) Toward a consistent model for strain accrual and release for the New Madrid Seismic Zone, central United States. J Geophys Res 116:B03311

Johnston AC (1996) Seismic moment assessment of earthquakes in stable continental regions; III, New Madrid 1811-1812, Charleston 1886 and Lisbon 1755. Geophys J Int 126(2):314-344

Kanamori H (1978) Quantification of earthquakes. Nature 271:411414

Kenner SJ, Segall P (2000) A mechanical model for intraplate earthquakes; application to the New Madrid seismic zone. Science 289(5488):2329-2332

Li Q, Liu M, Stein S (2009) Spatial-temporal complexity of continental intraplate seismicity: insights from geodynamic modeling and implications for seismic hazard estimation. Bull Seismol Soc Am 99(1). doi:10.1785/0120080005

Liu M, Stein S (2011) Aftershocks. In: Gupta H (ed) Encyclopedia of solid earth geophysics: Dordrecht. Springer, The Netherlands, pp 192-194

Liu M, Wang H (2012) Roaming earthquakes in China highlight midcontinental hazards. EOS 93(45):453-454

Liu M, Yang Y (2005) Contrasting seismicity between the North China and South China blocks: kinematics and geodynamic. Geophys Res Lett 32:L12310. doi:10.1029/2005GL023048

Liu M, Stein S, Wang H (2011) 2000 years of migrating earthquakes in North China: how earthquakes in midcontinents differ from those at plate boundaries: lithosphere. pp 128-132

Lockner DA, Okubo PG (1983) Measurements of frictional heating in granite. J Geophys Res 88(5):4313-4320

Luo G, Liu M (2010) Stress evolution and fault interactions before and after the 2008 great Wenchuan earthquake. Tectonophysics 491:127-140. doi:10.1016/j.tecto.2009.1012.1019

McGarr A, Gay NC (1978) State of stress in the Earth's crust. Ann Rev Earth Planet Sci 6:405-435
McKenna J, Stein S, Stein C (2007) Is the New Madrid seismic zone hotter and weaker than its surroundings? In: Mazzotti S, Stein S (eds) Continental intraplate earthquakes: science, hazard, and policy issues, Volume Special Paper 425. Boulder, Colorado, Geol. Soc. Am, pp 167-175

Parsons T (2002) Global Omori law decay of triggered earthquakes: large aftershocks outside the classical aftershock zone. J Geophys Res B 107(9):1-9

Reid HF (1910) The mechanics of the earthquake, the California earthquake of April 18, 1906. Report of the State Investigation Commission, vol. 2

Schweig ES, Ellis MA (1994) Reconciling short recurrence intervals with minor deformation in the New Madrid seismic zone. Science 264(5163):1308-1311

Stein S (2010) Disaster deferred: how new science is changing our view of earthquake hazards in the Midwest. Columbia University Press, New York

Stein S, Liu M (2009) Long aftershock sequences within continents and implications for earthquake hazard assessment. Nature 462(7269):87-89

Stein S, Liu M, Calais E, Li Q (2009) Mid-continent earthquakes as a complex system. Seismol Res Lett 80(4):551-553

Stein S, Geller RJ, Liu M (2012) Why earthquake hazard maps often fail and what to do about it. Tectonophysics 562-563:1-25

Tuttle MP, Schweig ES, Sims JD, Lafferty RH, Wolf LW, Haynes ML (2002) The earthquake potential of the New Madrid seismic zone. Bull Seismol Soc Am 92(6):2080-2089

Tuttle MP, Al-Shukri H, Mahdi H (2006) Very large earthquakes centered Southwest of the New Madrid seismic zone 5,000-7,000 years ago. Seismol Res Lett 77(6):755-770

Van Arsdale R (2000) Displacement history and slip rate on the Reelfoot fault of the New Madrid seismic zone. Eng Geol 55(4):219-226

Van Arsdale RB, TenBrink RK (2000) Late cretaceous and cenozoic geology of the New Madrid seismic zone. Bull Seismol Soc Am 90(2):345-356

Ward SN (1998) On the consistency of earthquake moment rates, geological fault data, and space geodetic strain; the United States. Geophys J Int 134(1):172-186

Zhang Q, Sandvol E, Liu M, (2009a), Lithospheric velocity structure of the New Madrid seismic zone: a joint teleseismic and local $P$ tomographic study. Geophys. Res. Lett 36(11):L11305

Zhang Q, Sandvol E, Liu M (2009b) Tomographic Pn velocity and anisotropy structure in the Central and Eastern United States. Bull Seismol Soc Am 99(1):422-427

Zhu RX, Yang JH, Wu FY (2012) Timing of destruction of the North China Craton. Lithos 149:51-60 